\title{
Przeszłe przyszłości
}

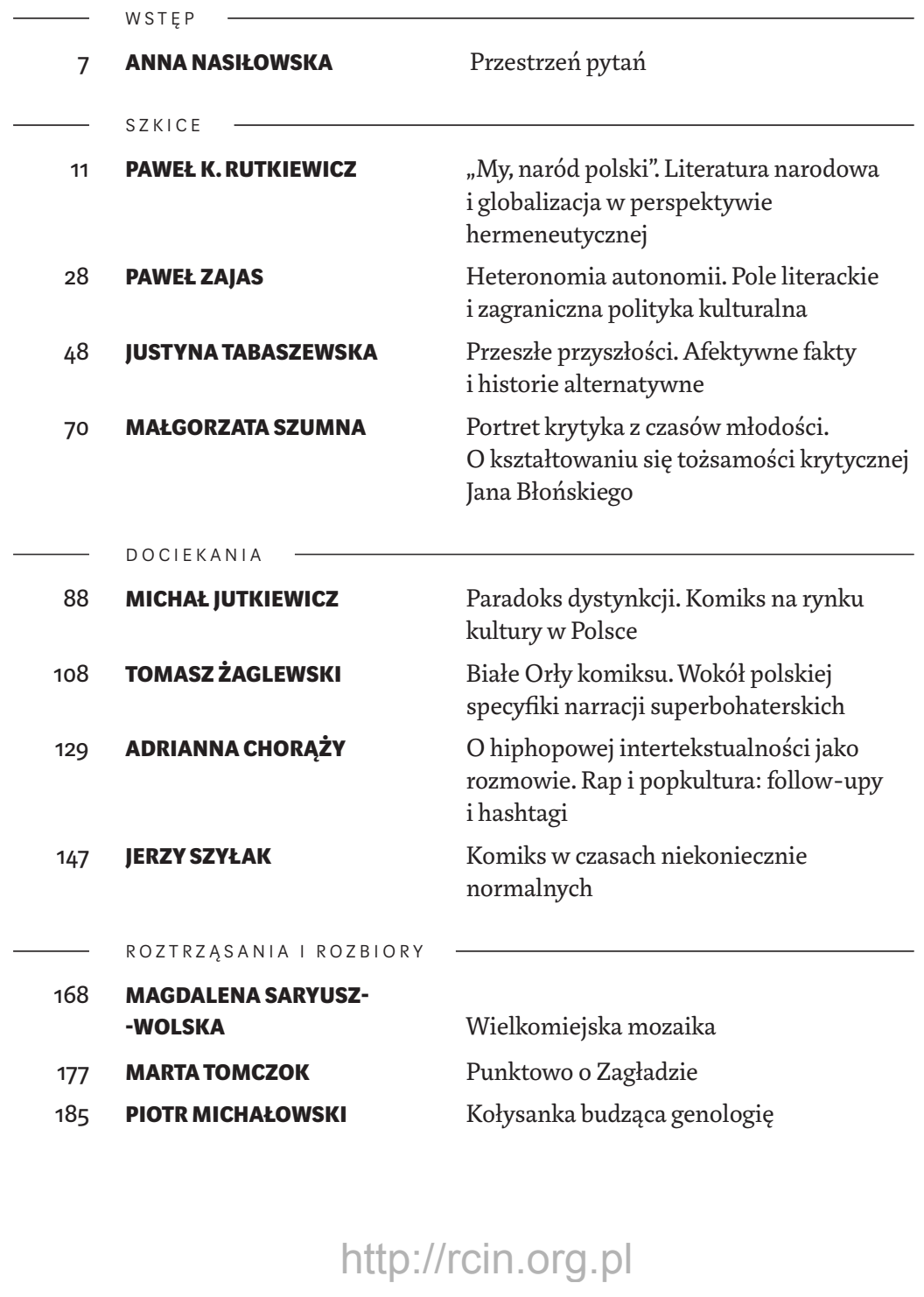




\begin{tabular}{|c|c|c|}
\hline 195 & JACEK ZWIERZYŃSKI & Rasa jako medium \\
\hline 209 & GABRIELA MATUSZEK & Strącona bogini - Inna od siebie \\
\hline 219 & ANNE CARSON & $\begin{array}{l}\text { Dekreacja. Wypowiadanie Boga: Safona, } \\
\text { Marguerite Porete i Simone Weil } \\
\text { Przeł. M.Topolski }\end{array}$ \\
\hline 239 & ELENA DWULYCZANSKA & $\begin{array}{l}\text { Fenomeny czasu fabularnego i przestrzeni } \\
\text { we współczesnej literaturze ukraińskiej } \\
\text { (na przykładzie prozy Wołodymyra } \\
\text { Jaworiwskiego) } \\
\text { Przeł. I. Boruszkowska }\end{array}$ \\
\hline 246 & PAWEt RAMS & $\begin{array}{l}\text { Andrzeja Stawara Brzozowskiego portret } \\
\text { podwójny }\end{array}$ \\
\hline 264 & RAFAt L. GÓRSKI & $\begin{array}{l}\text { Tłumaczenie bez oryginału, czyli o stylu } \\
\text { prozy Maurice'a S. Andrewsa, Joe Alexa } \\
\text { i Noëla Randona }\end{array}$ \\
\hline 277 & $\begin{array}{l}\text { PIOTR DE BOŃCZA } \\
\text { BUKOWSKI }\end{array}$ & $\begin{array}{l}\text { Od bliskości do obcości. Georg Brandes, } \\
\text { Polska i kwestia żydowska }\end{array}$ \\
\hline 301 & BEATA LAZARZ & $\begin{array}{l}\text { „[...] nawet zabić się nie mogę, bo chcę } \\
\text { widzieć". O spojrzeniu przez } £ z y\end{array}$ \\
\hline 313 & WOJCIECH TOMASIK & $\begin{array}{l}\text { Błądzenie Michałka. Nad mapą Warszawy } \\
\text { Prusa }\end{array}$ \\
\hline 330 & TOMASZ MAJEWSKI & Pożegnanie z Anną Zeidler-Janiszewską \\
\hline
\end{tabular}

